\title{
Rising incidence of morbidly adherent placenta and its association with previous caesarean section: a 15-year analysis in a tertiary hospital in Hong Kong
}

\author{
Katherine KN Cheng *, Menelik MH Lee
}

\section{A B S T R A C T}

Objectives: To identify the incidence of morbidly adherent placenta in the context of a rising caesarean delivery rate within a single institution in the past 15 years, and to determine the contribution of morbidly adherent placenta to the incidence of massive postpartum haemorrhage requiring hysterectomy.

Design: Case series.

Setting: A regional obstetric unit in Hong Kong.

Patients: Patients with a morbidly adherent placenta with or without previous caesarean section scar from 1999 to 2013.

Results: A total of 39 patients with morbidly adherent placenta were identified during 1999 to 2013. The overall rate of morbidly adherent placenta was $0.48 / 1000$ births, which increased from $0.17 / 1000$ births in 1999-2003 to 0.79/1000 births in 2009-2013. The rate of morbidly adherent placenta with previous caesarean section scar and unscarred uterus also increased significantly. Previous caesarean section (odds ratio $=24$ ) and co-existing placenta praevia (odds ratio $=585$ ) remained the major risk factors for morbidly adherent placenta. With an increasing rate of morbidly adherent placenta, more patients had haemorrhage with a consequent increased need for in the hysterectomy rate of morbidly adherent placenta in caesarean scarred uterus (19/25) compared with unscarred uterus $(8 / 14)$ was noted. This may have been due to increased detection of placenta praevia by ultrasound and awareness of possible adherent placenta in the scarred uterus, as well as more invasive interventions applied to conserve the uterus.

Conclusion: Presence of a caesarean section scar remained the main risk factor for morbidly adherent placenta. Application of caesarean section should be minimised, especially in those who wish to pursue another future pregnancy, to prevent the subsequent morbidity consequent to a morbidly adherent placenta, in particular, massive postpartum haemorrhage and hysterectomy.
Hong Kong Med J 2015;21:511-7
DOI: 10.12809/hkmj154599
KKN Cheng *, MB, ChB
MMH Lee, FHKCOG, FHKAM (Obstetrics and Gynaecology)
Department of Obstetrics and Gynaecology, Queen Elizabeth Hospital, Jordan, Hong Kong

peripartum hysterectomy. No significant difference * Corresponding author: chengkaning@gmail.com

New knowledge added by this study

The incidence of morbidly adherent placenta (MAP) including its precursor has increased over the last 15 years.

- MAP can occur in a scarred or an unscarred uterus with similar risks of massive postpartum haemorrhage or hysterectomy.

Implications for clinical practice or policy

- There is raised awareness of the possibility of MAP in a scarred or an unscarred uterus and the associated risks of massive postpartum haemorrhage and hysterectomy.

\section{Introduction}

Morbidly adherent placenta (MAP)-including placenta accreta, placenta increta, and placenta percreta-is a life-threatening condition often associated with massive postpartum haemorrhage (PPH) and sometimes hysterectomy. ${ }^{1,2}$ The condition results in significant maternal morbidity, maternal mortality, and socio-economic cost in terms of the need for invasive surgical intervention, prolonged hospitalisation, and admission to an intensive care unit.

The incidence of MAP is on the rise. ${ }^{3,4}$ In a US study, Wu et $\mathrm{al}^{5}$ reported an incidence of 1 in 533 births for the period from 1982 to 2002. This was much greater than a previous reported range of 1 in 4027 to 1 in 2510 births $^{6}$ or even 1 in 70000 births $^{7}$ in the 1970s to 1980s. A similar Irish retrospective study with 36 years of data reported a doubling of the incidence of placenta accreta in patients with previous caesarean section from 1.06 per 1000 
病態胎盤粘連不斷上升的發病率與有剖宮產史 的相關性：香港一所提供第三層醫療服務醫院的 15年資料分析

鄭嘉寧、李文軒

目的：分析一間醫院內病態胎盤粘連的發病率與剖宮產比率上升的關 係, 並探討病態胎盤粘連是否為產後大量出血須進行子宮切除術的原 因。

設計：病例系列。

安排：香港一個分區產科部門。

患者：1999至2013年期間，不論是否有剖宮產疮痕的病態胎盤粘連患 者。

結果：1999至2013年期間共有39例病態胎盤粘連，總比率為每1000 名出生嬰兒有 0.48 例。仔細分析兩段期間病態胎盤粘連的發生率有上 升趨勢：1999至2003年期間每1000名出生嬰兒有 0.17 例, 而在2009 至 2013 年期間每 1000 名出生嬰兒有 0.79 例。同期有剖宮產疤痕以及 無疮痕的病態胎盤粘連的比率亦有所上升。剖宮產史（比值比 $=24 ）$ 和共存性前置胎盤（比值比=585）仍然是病態胎盤粘連的主要危險因 素。隨着病態胎盤粘連的比率增加, 因出血須進行圍產期子宮切除術 的病例也不斷增長。比較有剖宮產疤痕 (19/25) 和無疮痕 $(8 / 14)$ 的 病例顯示兩組之間的子宮切除比率並無顯著差異。這可能是由於超聲 檢對前置胎盤有較高偵測率、對剖宮產疤痕而引致附着胎盤的警覺性 有所提高, 以及有更多具入侵性的干預措施來保護子宮有關。

結論：有剖宮產疮痕仍是病態胎盤粘連的主要危險因素。應盡量減少 剖腹產, 尤其是對於想繼續懷孕的婦女, 這可避免所導致的病態胎盤 粘連, 特別是產後大量出血和進行子宮切除術。 deliveries before 2002 to 2.37 per 1000 deliveries from 2003 to $2010 .^{8}$ A recent Canadian study also showed an incidence of 14.4 per 10000 deliveries in 2009 to $2010 .^{9}$ Although the majority of data suggested a rise in such trend, a few suggested otherwise. The American College of Obstetricians and Gynecologists accepted a rate of 1 in 2500 deliveries as the true incidence of the condition in $2002,{ }^{10,11}$ while a national case-control study in the UK suggested the incidence to be only 1.7 per 10000 pregnancies overall at the end of $2012 .^{12}$

Morbidly adherent placenta is most commonly associated with placenta praevia in women previously delivered by caesarean section. ${ }^{12-14}$ Despite some variation in the incidence of MAP, there are very few reported trends of MAP based on data of a single institution or within a similar population.

In this study, a retrospective review of data within a single institution in Hong Kong was performed to (a) identify the change in incidence of MAP that included placenta accreta, percreta and increta, in the context of a rising caesarean delivery rate within a single institution over the last 15 years, and (b) to determine the contribution of MAP to obstetric complications, in particular, massive $\mathrm{PPH}$ with consequent hysterectomy.

\section{Methods}

Patients with MAP at Queen Elizabeth Hospital, Hong Kong, over a 15-year period from 1 January 1999 to 31 December 2013 were retrospectively identified from the hospital database, Clinical Data Analysis and Reporting System (CDARS). The research protocol was approved by the hospital's ethics committee.

Diagnosis codes for 'previous caesarean section', 'placenta praeviae, 'adherent placenta' 'placenta accreta', 'placenta percreta', and 'placenta increta' were used. Labour ward records with cases of obstetrics-related hysterectomy or massive $\mathrm{PPH}$ (>1000 mL) were cross-examined along with the data from CDARS to ensure no cases of MAP were missed.

Morbidly adherent placenta was defined primarily by a histopathology report of an adherent placenta, in which there was invasion of placental tissue into the inner or outer myometrium or through the serosa of the uterus, and was termed placenta accreta, placenta increta, and placenta percreta, respectively. It was also defined clinically by operative reports of a difficult manual removal with no cleavage plane identified between the placenta and uterus, resulting in incomplete removal or need to leave the entire placenta in situ. Histopathology results were reviewed for each case where available.

The medical records including admission notes, operative record, and pathology reports in all of the cases were individually reviewed. Demographic data, obstetric history, the number and type of previous caesarean sections, and information on placenta site were collected. Details of associated complications, in particular massive $\mathrm{PPH}$, were reviewed. The subsequent management plan of MAP was noted and reviewed, and included (1) conservative management (leaving part of or the whole placenta in situ) with or without additional invasive intervention and follow-up, or (2) immediate invasive intervention (including uterine or iliac artery embolisation, balloon tamponade, uterine artery ligation, or hysterectomy).

Cases were then analysed in three different 5 -year intervals to identify any changes in the rate of MAP. These intervals were 1999 to 2003, 2004 to 2008, and 2009 to 2013. Cases of MAP were analysed in two different groups-a group with scarred uterus due to previous caesarean section and another group with unscarred uterus. Their incidence, associated risk factors, and morbidity associated with MAP were reviewed and compared.

Statistical analyses were performed using the Statistical Package for the Social Sciences (Windows version 19.0; SPSS Inc, Chicago [IL], US). Chi squared 
TABLE I. Number of deliveries, CS, CSP, and MAP separated into 5-year intervals

\begin{tabular}{lccccc}
\hline & $\mathbf{1 9 9 9 - 2 0 0 3}$ & $\mathbf{2 0 0 4 - 2 0 0 8}$ & $\mathbf{2 0 0 9 - 2 0 1 3}$ & Total & P value \\
\hline Total No. of deliveries & 23063 & 28064 & 30370 & 81497 & - \\
\hline CS & $4506(19.5 \%)$ & $6573(23.4 \%)$ & $8218(27.1 \%)$ & $19297(23.7 \%)$ & $<0.01$ \\
\hline Abnormal placentation (PP and MAP) & $274(1.2 \%)$ & $283(1.0 \%)$ & $364(1.2 \%)$ & $921(1.13 \%)$ & 0.11 \\
CS for repeated CS & $1314(5.7 \%)$ & $1790(6.4 \%)$ & $2688(8.9 \%)$ & $5792(7.0 \%)$ & $<0.01$ \\
MAP & $4(0.017 \%)$ & $11(0.039 \%)$ & $24(0.079 \%)$ & $39(0.048 \%)$ & 0.01 \\
\multicolumn{1}{c}{ MAP with previous CS } & $3(0.013 \%)$ & $6(0.021 \%)$ & $16(0.053 \%)$ & $25(0.031 \%)$ & 0.046 \\
\multicolumn{1}{c}{ MAP with unscarred uterus } & $1(0.004 \%)$ & $5(0.018 \%)$ & $8(0.026 \%)$ & $14(0.018 \%)$ & 0.01 \\
MAP among those who had CS for repeated CS & $3 / 1314(0.23 \%)$ & $6 / 1790(0.34 \%)$ & $16 / 2688(0.60 \%)$ & $25 / 5792(0.43 \%)$ & 0.286 \\
\hline
\end{tabular}

Abbreviations: $\mathrm{CS}=$ caesarean section; $\mathrm{CSP}=$ caesarean scar pregnancy; $\mathrm{MAP}=$ morbidly adherent placenta; $\mathrm{PP}=$ placenta praevia

test or Fisher's exact test for categorical variables and independent sample $t$ test or analysis of variance for continuous variables were applied for analysis. All statistical tests were two-tailed, and a P value of $<0.05$ was considered statistically significant.

\section{Results}

Over the 15-year study period, there were a total of 81497 deliveries in our hospital. The mean number of deliveries before 2004 was 4600 per year but this figure increased dramatically to a mean of 5800 per year from 2004 to 2013. This is likely due to the introduction of the 'Individual Visit Scheme' in July 2003, where travellers from Mainland China are allowed visits and to give birth in Hong Kong on an individual basis. The overall rate of caesarean section during the 15 -year period was $23.7 \%$ and was increased significantly throughout the years $(\mathrm{P}<0.01$; Table 1 and Fig 1$)$. As a result, the rate of caesarean section due to previous caesarean section also significantly increased from $5.7 \%$ in $1999-2003$ to $8.9 \%$ in $2009-2013$ ( $\mathrm{P}<0.01$; Table 1 and Fig 1$)$.

A total of 39 cases of MAP were identified. The overall rate of MAP was 0.48 per 1000 births, which has been increased significantly from 1999 to $2013(\mathrm{P}=0.01)$. Of the 39 cases of MAP, 25 cases were in a scarred uterus and all deliveries were by caesarean section; 14 cases were from an unscarred uterus, of which four were vaginal deliveries and 10 were caesarean section. There were three cases of placenta percreta and 36 cases of placenta accreta. The increasing rate of MAP persisted even after subcategorisation into previous caesarean section scar or unscarred uterus (Table 1 and Fig 2). There was also an increasing trend of MAP with caesarean section scar among cases that had repeated caesarean section, although the increase was not significant $(\mathrm{P}=0.286$; Table 1$)$.

The overall incidence of MAP in previous caesarean section was $0.43 \%$ compared with only $0.018 \%$ in those with an unscarred uterus. The odds

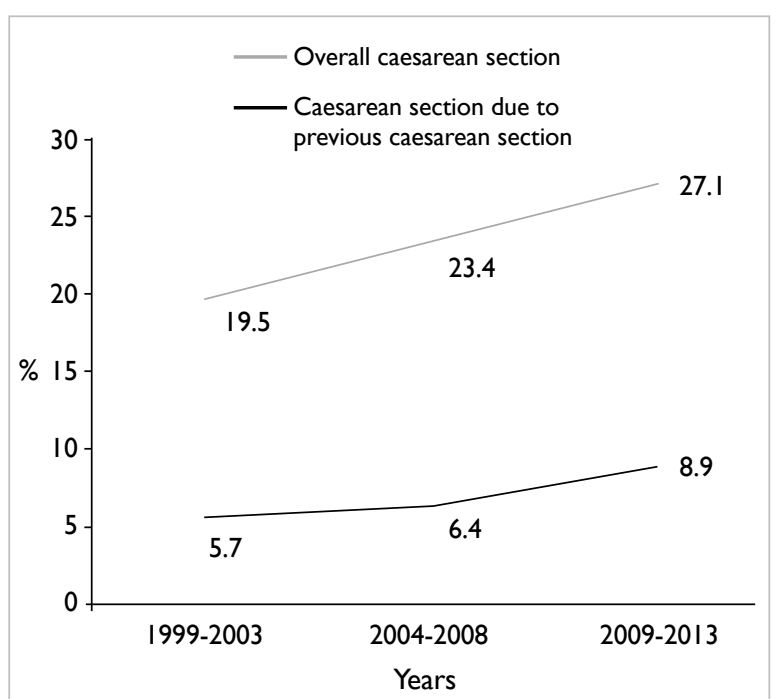

FIG I. Caesarean section rate from 1999 to 2013

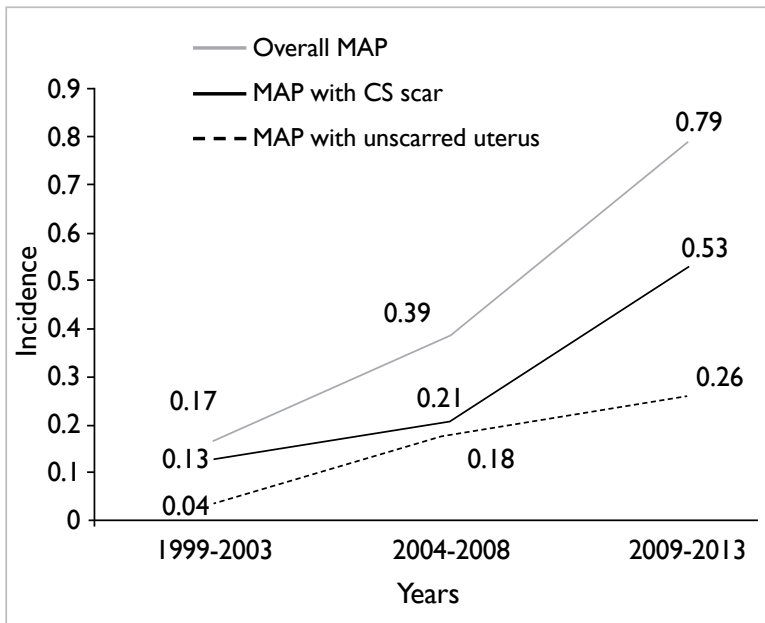

FIG 2. The incidence of MAP from 1999 to 2013 (per 1000 birth)

Abbreviations: $\mathrm{CS}=$ caesarean section; $\mathrm{MAP}=$ morbidly

adherent placenta 
ratio (OR) of MAP in previous caesarean section was 24 compared with that of unscarred uterus $(\mathrm{P}<0.05$; 95\% confidence interval [CI], 12.2-45.2).

Among all the cases of placenta praevia during the study period, the incidence did not differ significantly with time and remained an average of $1.13 \%$ ( $\mathrm{P}=0.11$; Table 1 ). Among the 39 cases of MAP, 34 cases had pre-existing placenta praevia. Placenta praevia remained a major risk factor in the development of MAP (OR=585; 95\% CI, 228.31399.7).

Cases with MAP and a previous caesarean section were compared with those with an unscarred uterus. The presence of placenta praevia with a previous scar increased the risk of MAP significantly $(\mathrm{P}<0.01$; Table 2). There were no significant differences between the two groups for the majority of other additional underlying risk factors for MAP. These included mean parity, maternal age, gestational age at delivery, and the number of previous surgical termination of pregnancy or surgical evacuations (Table 2). Overall, there was one case of MAP following in-vitro fertilisation-induced pregnancy but no cases had a history of hysteroscopic surgery or a history of uterine artery embolisation.

\section{Management of morbidly adherent placenta in scarred versus unscarred uterus}

Among the 39 cases of MAP, 14 cases were from an unscarred uterus, thus there had been no antenatal suspicion of a possible MAP. Among the remaining 25 cases where MAP was found in a scarred uterus, 24 cases had placenta praevia diagnosed on antenatal ultrasonography (USG) and one case had no previous antenatal USG documentation of placental site. In three cases, there was antenatal suspicion of placenta accreta with additional measurement made of the lower segment thickness by USG. None of the three cases had signs of MAP, thus no antenatal diagnosis was made or caesarean hysterectomy planned. For all cases with co-existing placenta praevia diagnosed antenatally, counselling including the risk of $\mathrm{PPH}$, need for multiple medical/surgical interventions and hysterectomy as a last resort was given prior to caesarean section.

In terms of the diagnosis of MAP, 27 (69\%) cases were confirmed histologically following hysterectomy. The remaining 12 were diagnosed clinically. Among those confirmed histologically, 19 cases were from a scarred uterus and eight from an unscarred uterus. Of 19 cases from a scarred uterus, 11 had undergone previous intervention (uterine artery embolisation, uterine artery ligation, or balloon tamponade) before hysterectomy compared with one in eight cases of unscarred uterus (Table 3).

Conservative management with the MAP tissue left in situ was applied in 12 (31\%) cases of MAP (6 cases from each group): three of the scarred uterus cases required additional invasive interventions compared with two of the six cases with unscarred uterus (Table 3). Three cases defaulted from subsequent follow-up and the remaining nine cases resolved completely in 8 to 49 weeks' time.

The majority of cases of MAP in patients with scarred and unscarred uterus were complicated by massive PPH of $>1500 \mathrm{~mL}$ ( $80 \%$ vs $71 \%$ ). The rate of hysterectomy in both groups was high: $76 \%$ in the scarred uterus group and $57 \%$ in unscarred uterus group (Table 3), although the difference was not significant.

\section{Overall morbidity of morbidly adherent placenta}

Throughout the 15-year study period, there was a significant increase in the proportion of MAP associated with massive $\mathrm{PPH}(\mathrm{P}=0.048)$. Thus there was a consequent increased trend, although not significant, in the need for invasive intervention and hysterectomy (Tables 4 and 5), which is a life-saving last-resort procedure in the management of massive $\mathrm{PPH}$.

\section{Discussion}

The data derived from this retrospective study demonstrate a significant increase in the total

TABLE 2. Baseline characteristics and risk factors for morbidly adherent placenta between scarred and unscarred uterus

\begin{tabular}{lccc}
\hline Patient's characteristic & With previous CS (n=25) & Unscarred uterus (n=14) & P value \\
\hline Mean age (years) & 34.64 & 32.64 & 0.057 \\
Mean gestational age at delivery (years) & 35.49 & 36.73 & 0.438 \\
No. of previous STOP/D\&C & 1.24 & 1.86 & 0.227 \\
History of TOP & $14(56 \%)$ & $10(71 \%)$ & 0.342 \\
Parity & 1.4 & 0.79 & 0.07 \\
Placenta praevia & $25(100 \%)$ & $9(64 \%)$ & $<0.01$ \\
\hline
\end{tabular}

Abbreviations: CS = caesarean section; D\&C = dilatation and curettage; STOP = surgical termination of pregnancy;TOP = termination of pregnancy 
TABLE 3. Comparing massive postpartum haemorrhage and invasive management of morbidly adherent placenta between scarred and unscarred uterus

\begin{tabular}{|c|c|c|c|c|}
\hline & With previous CS $(n=25)$ & Unscarred uterus $(n=14)$ & $P$ value & OR (with previous CS) \\
\hline Hysterectomy & $19(76 \%)$ & $8(57 \%)$ & 0.221 & $2.38(0.59-9.6)$ \\
\hline Invasive intervention prior to hysterectomy & 11 & 1 & & \\
\hline UAE & 6 & 1 & & \\
\hline Uterine artery ligation & 4 & 0 & & \\
\hline Balloon tamponade & 1 & 0 & & \\
\hline Conserve uterus & $6(24 \%)$ & $6(43 \%)$ & & \\
\hline Invasive intervention with conserving uterus & 3 & 2 & & \\
\hline UAE & 2 & 2 & & \\
\hline Uterine artery ligation & 0 & 0 & & \\
\hline Balloon tamponade & 1 & 0 & & \\
\hline Massive postpartum haemorrhage (>1500 mL) & $20(80 \%)$ & $10(71 \%)$ & 0.542 & $1.6(0.35-1.3)$ \\
\hline
\end{tabular}

Abbreviations: $\mathrm{CS}$ = caesarean section; $\mathrm{OR}=$ odds ratio; $\mathrm{UAE}=$ uterine artery embolisation

TABLE 4. Morbidity of patients with morbidly adherent placenta from 1999 to 2013

\begin{tabular}{lcccc}
\hline & $\mathbf{1 9 9 9 - 2 0 0 3 ~ ( n = 4 ) ~}$ & $\mathbf{2 0 0 4 - 2 0 0 8 ~ ( n = 1 1 ) ~}$ & 2009-2013 (n=24) & P value \\
\hline Need for invasive management* & $2(50 \%)$ & $10(91 \%)$ & $20(83 \%)$ & 0.277 \\
Hysterectomy & $2(50 \%)$ & $10(91 \%)$ & $15(63 \%)$ & 0.166 \\
Massive postpartum haemorrhage $(>1500 \mathrm{~mL})$ & $2(50 \%)$ & $11(100 \%)$ & $17(71 \%)$ & 0.048 \\
\hline
\end{tabular}

* Invasive management: balloon tamponade, uterine artery embolisation, uterine artery ligation and hysterectomy, etc

TABLE 5. Rate of peripartum hysterectomy for all causes and for morbidly adherent placenta (MAP) from 1999 to 2013 , separated into 5-year intervals

\begin{tabular}{llccc}
\hline & $\mathbf{1 9 9 9 - 2 0 0 3}$ & $\mathbf{2 0 0 4 - 2 0 0 8}$ & $\mathbf{2 0 0 9 - 2 0 1 3}$ & P value \\
\hline Total No. of deliveries & 23063 & 28064 & 30370 & - \\
Total peripartum hysterectomy for all causes & $4(0.017 \%)$ & $21(0.075 \%)$ & $26(0.086 \%)$ & 0.004 \\
\% Of hysterectomy related to MAP & $2(50 \%)$ & $10(48 \%)$ & $15(58 \%)$ & 0.067 \\
\hline
\end{tabular}

number of deliveries and caesarean sections from 1999 to 2013. With an increasing caesarean section rate, the number of repeated caesarean sections also increased. Possible explanations include the high caesarean section rates in China and concerns about the reported 4.5 per 1000 risk of previous caesarean scar rupture. ${ }^{15}$ An alternative explanation is the large proportion of patients who declined a vaginal birth after a previous caesarean section or who declined induction of labour after a previous caesarean section. It has been reported that up to $32 \%$ to $46 \%$ of patients with a history of caesarean section decline induction. ${ }^{16}$ The rate of MAP hence increased as a result of more previous caesarean sections and concurs with the findings from other countries..$^{3-8}$ Our study further demonstrated an almost tripling of incidence of MAP in the presence of previous caesarean section from 0.23 to 0.60 per 1000 births during 2009 to 2013 . This may be due to an increasing awareness of the increasing trend of MAP, especially in those with a caesarean scar.

Previous caesarean section scar has been identified as one of the most important risk factors for MAP. Our study demonstrated a 24 times greater likelihood of developing MAP with previous caesarean section scar compared with unscarred uterus. Placenta praevia in the presence of a previous caesarean section scar was 585 times more likely to develop into a MAP. Nonetheless our data failed to determine other reported demographics ${ }^{17}$ and risk 
factors such as mean parity, maternal age, gestational age at delivery, and previous surgical termination or surgical evacuation. Previous surgery on the uterus other than caesarean section (eg myomectomy) may also predispose to MAP but among our cases of adherent placenta, no patient had such a history so comparisons could not be made. As a result, every effort should be made to avoid caesarean section delivery and hence reduce subsequent MAP development.

Morbidly adherent placenta was more likely in a scarred uterus although it could also occur in an unscarred uterus. Although the majority of patients with MAP in our study had a caesarean scar, $36 \%$ had an unscarred uterus. The mean number of surgical termination of pregnancy or surgical evacuation of the uterus in the unscarred uterus group was 1.86 compared with 1.24 in the caesarean section scarred uterus group. In addition, in the unscarred uterus group, $71 \%$ of patients had a history of surgical termination of pregnancy compared with $56 \%$ in the caesarean section scarred uterus group, although the difference was not significant. A recent case study has reported an abnormally invasive placenta as a result of uterine scarring in a patient with Asherman's syndrome. ${ }^{18}$ Therefore, awareness of the possible development of MAP is important in pregnant women with a history of intrauterine procedure without caesarean section scar or placenta praevia.

The management of patients with complications associated with MAP can be challenging. Patients are more likely to develop massive $\mathrm{PPH}$ with a consequent need for intra-operative invasive intervention (eg balloon tamponade, uterine artery ligation/embolisation, and hysterectomy) and hysterectomy compared with those with a normally adherent placenta. ${ }^{19}$

Our data clearly demonstrated an increase in the incidence of massive $\mathrm{PPH}$ as the incidence of MAP increases. The rate of peripartum hysterectomy associated with MAP also showed an increasing trend, albeit insignificant. This could be due to advances in management, including increasing USG detection of placenta praevia in the early antenatal period and awareness of a possibly adherent placenta in cases with a scarred uterus that facilitates a delivery plan, as well as multiple interventions (balloon tamponade, uterine artery embolisation, uterine artery ligation) attempted in cases with MAP to conserve the uterus as far as possible. This was reflected by the increased need for invasive interventions throughout the study period although not to a significant degree, possibly due to the small sample size.

\section{Limitations}

This was a retrospective overview of our hospital data over the last 15 years. Data obtained during the earlier years when the hospital's Clinical Record System was first introduced may be inaccurate. Similarly, historical data were available for only this 15 -year period. Given the overall low incidence of MAP and the limited data available, the strength of the statistical significance may well be challenged. In addition, caesarean scar pregnancy, which is a precursor of MAP, was not included in this study as the number of cases was too small and no systemic data were available. Previous studies have shown that leaving the placenta in situ can reduce the rate of hysterectomy. ${ }^{20}$ This issue was not investigated in this study.

\section{Conclusion}

This study demonstrated that the incidence of MAP has increased over the last 15 years. The results also remind clinicians that MAP is much more likely to occur if a previous caesarean scar is present $(\mathrm{OR}=24)$, in particular when it is associated with a placenta praevia $(\mathrm{OR}=585)$. The increased caesarean section rate and subsequent previous caesarean section scar were major causes for such increase. Morbidly adherent placenta resulted in an increasing, albeit insignificant, trend for massive $\mathrm{PPH}$, and the need for multiple invasive interventions or hysterectomy over the last 15 years. Early suspicion and diagnosis is essential to prevent major obstetric complications, as well as to aid management of massive $\mathrm{PPH}$ resulting from placenta complications. Every effort should be made to avoid unnecessary caesarean section, not only to meet the international caesarean section rate target but also to reduce the overall incidence of MAP that may result in significant maternal morbidity and mortality, as well as socioeconomic costs.

\section{References}

1. Silver RM, Landon MB, Rouse DJ, et al. Maternal morbidity associated with multiple repeat cesarean deliveries. Obstet Gynecol 2006;107:1226-32.

2. Esakoff TF, Sparks TN, Kaimal AJ, et al. Diagnosis and morbidity of placenta accreta. Ultrasound Obstet Gynecol 2011;37:324-7.

3. Chattopadhyay SK, Kharif H, Sherbeeni MM. Placenta praevia and accreta after previous caesarean section. Eur J Obstet Gynecol Reprod Biol 1993;52:151-6.

4. To WW, Leung WC. Placenta previa and previous cesarean section. Int J Gynaecol Obstet 1995;51:25-31.

5. Wu S, Kocherginsky M, Hibbard JU. Abnormal placentation: twenty-year analysis. Am J Obstet Gynecol 2005;192:1458-61.

6. Pridjian G, Hibbard JU, Moawad AH. Cesarean: changing the trends. Obstet Gynecol 1991;77:195-200.

7. Breen JL, Neubecker R, Gregori CA, Franklin JE Jr. Placenta accreta, increta, and percreta. A survey of 40 cases. Obstet Gynecol 1977;49:43-7.

8. Higgins MF, Monteith C, Foley M, O'Herlihy C. Real increasing incidence of hysterectomy for placenta accreta following previous caesarean section. Eur J Obstet Gynecol 
Reprod Biol 2013;171:54-6.

9. Mehrabadi A, Hutcheon JA, Liu S, et al. Contribution of placenta accreta to the incidence of postpartum hemorrhage and severe postpartum hemorrhage. Obstet Gynecol 2015;125:814-21.

10. Timor-Tritsch IE, Monteagudo A. Unforeseen consequences of the increasing rate of cesarean deliveries: early placenta accreta and cesarean scar pregnancy. A review. Am J Obstet Gynecol 2012;207:14-29.

11. ACOG Committee on Obstetric Practice. ACOG Committee opinion. Number 266, January 2002: placenta accreta. Obstet Gynecol 2002;99:169-70.

12. Fitzpatrick KE, Sellers S, Spark P, Kurinczuk JJ, Brocklehurst $\mathrm{P}$, Knight M. Incidence and risk factors for placenta accreta/ increta/percreta in the UK: a national case-control study. PLoS One 2012;7:e52893.

13. Romero R, Hsu YC, Athanassiadis AP, et al. Preterm delivery: a risk factor for retained placenta. Am J Obstet Gynecol 1990;163:823-5.

14. Parazzini F, Dindelli M, Luchini L, et al. Risk factors for placenta praevia. Placenta 1994;15:321-6.

15. Lydon-Rochelle M, Holt VL, Easterling TR, Martin DP.
Risk of uterine rupture during labor among women with a prior cesarean delivery. N Engl J Med 2001;345:3-8.

16. Dodd JM, Crowther CA, Grivell RM, Deussen AR. Elective repeat caesarean section versus induction of labour for women with a previous caesarean birth. Cochrane Database Syst Rev 2014;(12):CD004906.

17. Miller DA, Chollet JA, Goodwin TM. Clinical risk factors for placenta previa-placenta accreta. Am J Obstet Gynecol 1997;177:210-4.

18. Engelbrechtsen L, Langhoff-Roos J, Kjer JJ, Istre O. Placenta accreta: adherent placenta due to Asherman syndrome. Clin Case Rep 2015;3:175-8.

19. Lee MM, Yau BC. Incidence, causes, complications, and trends associated with peripartum hysterectomy and interventional management for postpartum haemorrhage: a 14-year study. Hong Kong I Gynaecol Obstet Midwifery 2013;13:52-60.

20. Fitzpatrick KE, Sellers S, Spark P, Kurinczuk JJ, Brocklehurst P, Knight M. The management and outcomes of placenta accreta, increta, and percreta in the UK: a population-based descriptive study. BJOG 2014;121:6271. 